\title{
SARIMA Model for Forecasting Price Indices Fluctuations
}

\author{
N. Sonai Muthu, K. Senthamarai Kannan, V. Deneshkumar and P. Thangasamy
}

\begin{abstract}
In day-to-day life, the price level fluctuations in the Consumer Price Index (CPI) goods and service. So, the retail consumers are affecting by that price level changes, who are on the demand side of the economy. The main objective of this work is to forecast such selected factors of CPI in urban and rural areas of India, like: Food and Beverages, Pan, Tobacco and Intoxicants, Fuel and Light and Education and also compute the inflation rate for those four main variables in all India.
\end{abstract}

\section{Keywords - ADF, KPSS, SARIMA, CPI and RBI.}

\section{INTRODUCTION}

The consumer price index is one of the economic indicators of the RBI in India. This economic indicator is used to determine the price in which way will go the price for consumer goods and services in India and around the world at monthly. This economic indicator is still to go the rising up at currently. It is the most widely used measure of inflation and, by proxy, of the effectiveness of the government's economic policy. CPI is calculated for a fixed basket of goods and services that may or may not be altered by the government from time to time. It is a macroeconomic indicator that measures inflation at year on year. It is used as an essential economic tool by central and state governments, the Reserve Bank of India (RBI), which is the central bank of our country for maintaining money supply, price stability.

Consumer price index is calculated as a percentage. It is a comparison of the general price level in the markets in a particular time period from a time frame in the past. This is known as the base year. CPI, therefore, is calculated by referring to a base year which is a benchmark. The base year is monitored by the Central Statistics Office (CSO), Ministry of Statistics and Programme Implementation (Mospi) and changes from time to time. Last, the base year was shifted to 2012 from 2010. This was effective from January 2015 onwards.

This data have several main commodities in the all India (urban area, rural area and both urban \& rural area). In this paper the selected variables such as, food and beverages (FB), pan, tobacco and intoxicants (PTI), education (ED), fuel and light (FL)) from CPI of all India data in the RBI database for the period of January 2013 to December 2020.The each and every four commodities have 96 observed values. Two models have been suggested by the researchers [12]. One is a

Published on November 8, 2021

N. S. Muthu, Department of Statistics, Manonmaniam Sundaranar University, Abishekapatti, Tirunelveli, India.

(corresponding e-mail: sonaimuthu@gmail.com)

K. S Kannan, Department of Statistics, Manonmaniam Sundaranar University, Abishekapatti, Tirunelveli, India.

(e-mail:senkannan2002@gmail.com) linear model and second one is a non-linear model. These two models foresaw the CPI in comparison.

A short-term CPI estimated to test the auto-correlation of the residual serial models with ARIMA [6]. In Nigeria's inflation rate, between 1980 and 2010. The anticipated CPI in Nigeria was predicted for five years [1]. The SARIMA model was implemented for short-term traffic flow prediction $[2,8]$ with limited inputs and traffic flow prediction is an essential part of most applications with the Smart Transmission System. Time series model have examined and compared with neural network model for agricultural crop prediction [3].

The Consumer Price Index using Box and Jenkins Method is predicted [11]. For the years 1970 to 2006, empirical analysis data for Pakistan was used [7]. They predicted different ARIMA models using the Box-Jenkins method to predict. The CPI, which reflects the prices paid by the consumer for goods and services, is a common Indian economy indicator [5], [13].

The annual CPI time series data from 1986 to 2018 were used for the time series econometric model in Bangladesh for CPI forecasting. For a predictive Consumer Price Indicator using monthly time series data. The financial data for analyze the trend prediction and it helpful for decision makers to make decisions in case of uncertainty [4]. Time series model compared with ARIMA errors in covariant time. In order to make short-term forecasting for the CPI [10] identified and estimated an ARIMA Model.

This study has been examined about the future behavior of consumer price index in India's Urban and Rural areas. In this study, used SARIMA method in the time series analysis for forecast and modeling the consumer price index in India's Urban and Rural areas during January 2021 to December 2022 and has been found the inflation rate for the period of January 2021 to December 2022.

\section{Methodology}

The Dickey Fulling Augmented (ADF) test is a stationary root test unit. With serial correlation, the Augmented DickeyFuller test may be employed. A negative value is utilized for the increased Dickey-Fuller (ADF) statistic used in the test. The more negative the hypothesis of a unit root at given confidence level is the greater rejection.

The test statistic is:

V. Deneshkumar, Department of Statistics, Manonmaniam Sundaranar University, Abishekapatti, Tirunelveli, India. (e-mail: vdenesh77@gmail.com)

P. Thangasamy Department of Statistics, Manonmaniam Sundaranar University, Abishekapatti, Tirunelveli, India.

(e-mail: pksamy190699@gmail.com) 


$$
D F_{\tau}=\frac{\hat{\gamma}}{S E(\hat{\gamma})}
$$

where, $\hat{\gamma}$ is the unit root.

It may be compared with the critical value for the DickeyFuller test to determine the test statistics. Since this test is asymmetrical, this is just negative values. If the computed test data are lower (more negative) than the critical value, then $\mu=0$ is rejected at $\alpha=0.05$ and there are no single unit roots. The provided series is thus a fixed series. Alternative $\mu<0$ rejected at $\alpha=0,05$ otherwise the provided series has a root unit and a non-stationary series.

The Kwiatkowski-Phillipsen-Schmidt-Shin (KPSS) test describes whether the time series are stationary or nonstationary owing to an average or linear trend. The zero hypotheses and alternatives for the KPSS test are different from the ADF. The statistics for the KPSS test are the Lagrange multiplier (LM) or score data $\sigma_{\varepsilon}^{2}=0$ against the alternative that $\sigma_{\varepsilon}^{2}>0$ and is given by:

$$
K P S S=\left(T^{-2} \sum_{t=1}^{T} \hat{S}_{t}^{2}\right) / \hat{\lambda}^{2}
$$

where $\hat{S}_{t}^{2}=\sum_{j=1}^{t} \hat{u}_{j}, \hat{u}_{j}$ is the residual of a regression of $y_{t}$.

If the calculated test statistic is less than the critical value, then the null hypothesis of $\sigma_{\varepsilon}^{2}=0$ is rejected at $\alpha=0.05$. Therefore, the given series is a non-stationary series. Otherwise, rejected alternative hypothesis $\sigma_{\varepsilon}^{2}>0$ at $\alpha=$ 0.05 . Then the given series is a stationary series.

A non-seasonal ARIMA is commonly denoted as ARIMA $(p, d, q)$. Where, $p$ is the order of $A R(p), d$ is the order of differencing the original data and $q$ is the order of $\mathrm{MA}(\mathrm{q})$.

Similarly, A seasonal ARIMA is generally denoted as Seasonal ARIMA (p,d,q)(P,D,Q)s.

where, $s$ is the of periods in every season, $p \& P$ are the non-seasonal \& seasonal order of AR respectively, $\mathrm{d} \& \mathrm{D}$ are the non-seasonal \& seasonal order of differencing the original data respectively and $\mathrm{q} \& \mathrm{Q}$ are the non-seasonal \& seasonal order of MA respectively.

The Seasonal ARIMA model is defined as:

$$
\Phi_{P}\left(B^{s}\right) \phi_{p}(B)(1-B)^{d}\left(1-B^{s}\right)^{D} Z_{t}=\theta_{q}(B) \Theta_{Q}\left(B^{s}\right) a_{t}
$$

where, the stationary AR operator is $\phi_{p}(B)=\left(1-\phi_{1}(B)-\right.$ $\left.\phi_{2}\left(B^{2}\right)-\cdots-\phi_{p}\left(B^{p}\right)\right)$; the invertible MA operator is $\theta_{q}(B)=\left(1-\theta_{1}(B)-\theta_{2}\left(B^{2}\right)-\cdots-\theta_{q}\left(B^{q}\right)\right)$.

When $\mathrm{d}=0$, the original process is stationary and $\theta_{0}$ is related to the mean of the process, ie., $\theta_{0}=\left(1-\phi_{1}-\phi_{2}-\right.$ $\left.\cdots-\phi_{p}\right)$.

When $\mathrm{d} \geq 1$, then $\theta_{0}$ is called the deterministic trend.

The seasonal AR operator is $\Phi_{P}\left(B^{s}\right)=\left(1-\Phi_{1}\left(B^{s}\right)-\right.$ $\left.\Phi_{2}\left(B^{2 S}\right)-\cdots-\Phi_{P}\left(B^{P S}\right)\right)$.

The seasonal MA operator is $\Theta_{Q}\left(B^{S}\right)=\left(1-\Theta_{1}\left(B^{s}\right)-\right.$ $\left.\Theta_{2}\left(B^{2 s}\right)-\cdots-\Theta_{Q}\left(B^{Q s}\right)\right)$.

The series $a_{t}$ is a Gaussian $N\left(0, \sigma^{2}\right)$ white noise process.

Model Validation using The Ljung-Box Test:

The Ljung and Box developed the standard portmanteau test to test that the data is a realization of a powerful white noise. The statistic of this test is:

$$
Q(m)=n(n+2) \sum_{k=1}^{m} \frac{r_{k}^{2}}{(n-k)}
$$

where, $\mathrm{n}$ is the sample size, $r_{k}$ is the autocorrelation of the sample at k-lag and $\mathrm{m}$ is the lag order that should be stated.

This test is a one-sided test. So, that calculated $\mathrm{p}$ - value is should be compared with specified significance level $(\alpha=$ 0.05 ). The null hypothesis of this test is $\mathrm{H} 0$ : The given sample is distributed as independently and against hypothesis is $\mathrm{H} 1$ : The given sample is not distributed as independently.

\section{Inflation of CPI:}

To measure inflation, first has to estimate how much the CPI percentage has increased in comparison to the same period of the previous year. When prices fall, it is called deflation (negative inflation).

The formula for Inflation rate is:

$$
\text { Inflation rate of } C P I=\left[\frac{\left(C P I_{C}-C P I_{P}\right)}{C P I_{P}}\right] \times 100
$$

where CPIC - is the CPI for current year \& CPIP - is the CPI for previous year.

\section{Computational Procedures}

The following selected factors of CPI in urban and rural areas of India, like: Food and Beverages, Pan, Tobacco and Intoxicants, Fuel and Light and Education are considered for forecast. For this study, the data of CPI for all India collected based on information from the Reserve Bank of India's (RBI) database (https://www.rbi.org.in).

From the Table I the result of KPSS test \& ADF test for transformed data of target variables of this study. Now, conclude that the $p$-values of ADF test for all main variables are lesser than the $5 \%$ level of significance and the p-values of KPSS test for all main variables are greater than the 5\% level of significance.

From KPSS test, hence the transformed data of eight target variables did not provide the sufficient evidence for rejecting the null hypothesis at 5\% level of significance. From ADF test, hence the transformed data of eight target variables did not provide the sufficient evidence for rejecting the alternative hypothesis at $5 \%$ level of significance.

From the above two stationary test, the transformed series of eight target series are stationary series and of these mean and variance are constant.

TABLE I: RESULTS FOR KPSS AND ADF TEST

\begin{tabular}{ccccc}
\hline \hline \multirow{2}{*}{$\begin{array}{c}\text { Stationary } \\
\text { Tests }\end{array}$} & \multicolumn{2}{c}{ KPSS Test } & \multicolumn{2}{c}{ ADF Test } \\
\cline { 2 - 5 } & Statistic & $\mathrm{p}$-value & Statistic & $\mathrm{p}-$ value \\
\hline \hline FBR & 0.1371 & 0.1 & -4.3395 & 0.0004 \\
PTIR & 0.1372 & 0.1 & -11.8875 & $5.98 \mathrm{e}-22$ \\
EDR & 0.1095 & 0.1 & -9.1856 & $2.19 \mathrm{e}-15$ \\
FLR & 0.4248 & 0.1 & -3.0753 & 0.0284 \\
FBU & 0.2171 & 0.1 & -4.3646 & 0.0003 \\
PTIU & 0.1245 & 0.1 & -5.5427 & $1.68 \mathrm{e}-06$ \\
EDU & 0.3044 & 0.1 & -3.6727 & 0.0045 \\
FLU & 0.1468 & 0.1 & -4.4263 & 0.0003 \\
\hline \hline
\end{tabular}



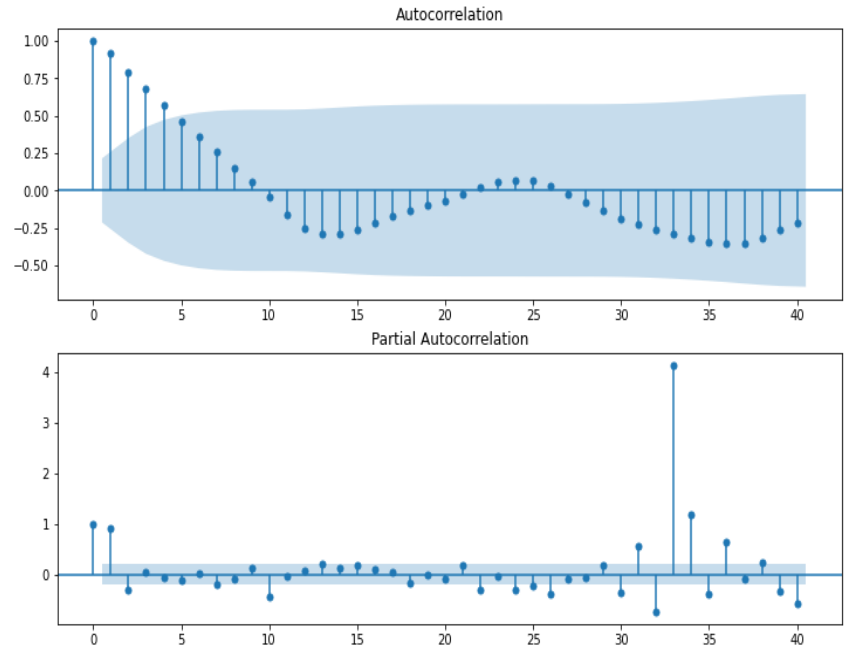

Fig. 1. ACF and PACF for food and beverages in rural.
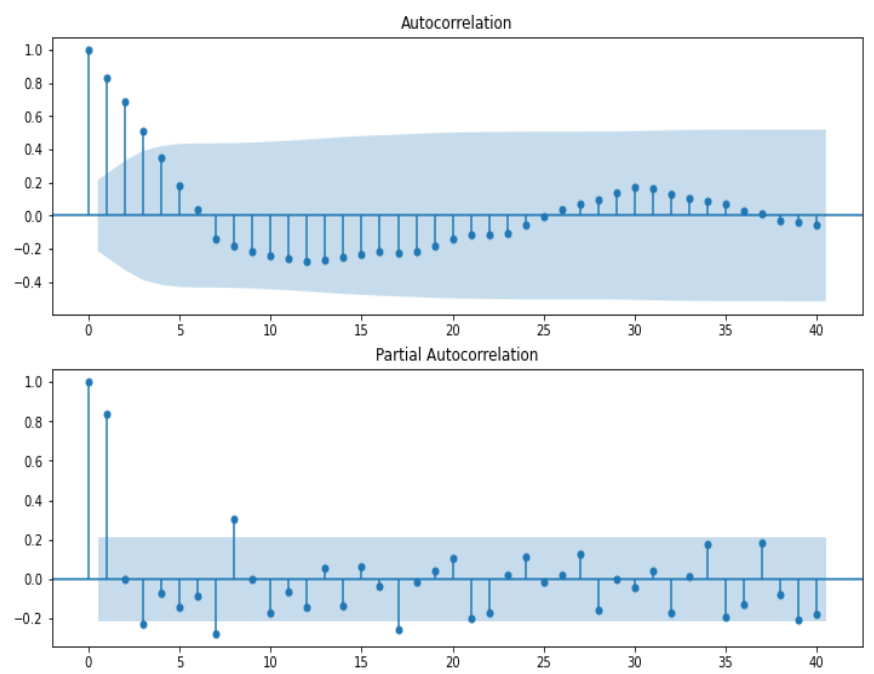

Fig. 2. ACF and PACF for pan, tobacco, and intoxicants in rural.
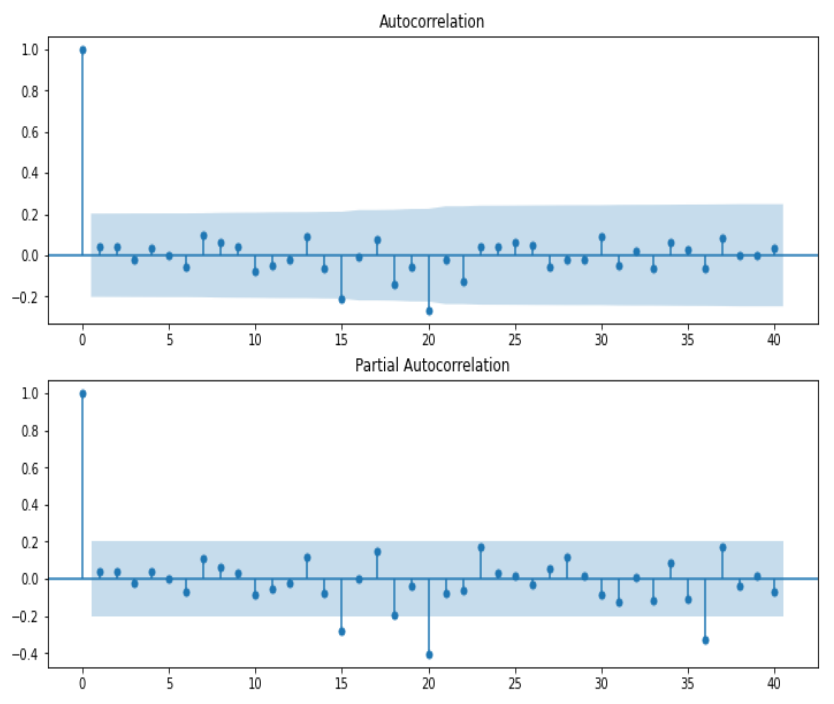

Fig. 3. ACF and PACF for education in rural.
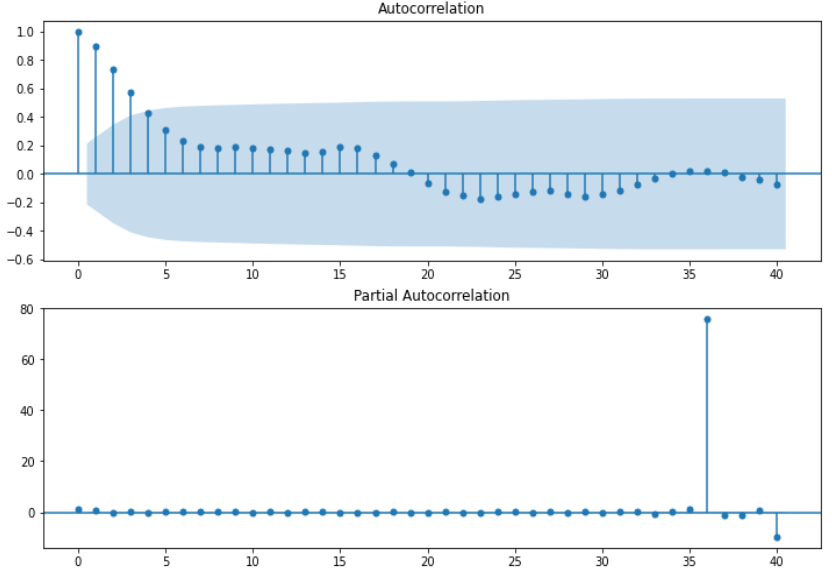

Fig. 4. ACF and PACF for fuel and light in rural.
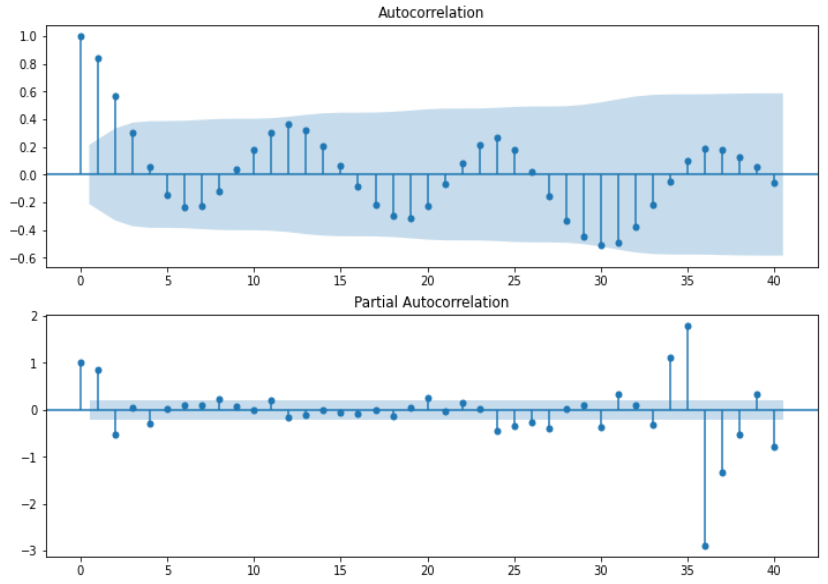

Fig. 5. ACF and PACF for food and beverages in urban.
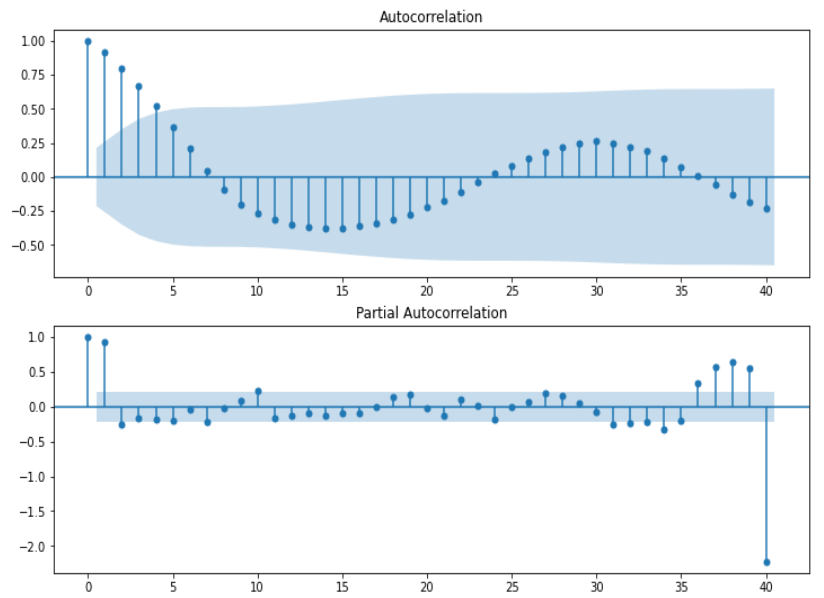

Fig. 6. ACF and PACF for pan, tobacco, and intoxicants in urban.
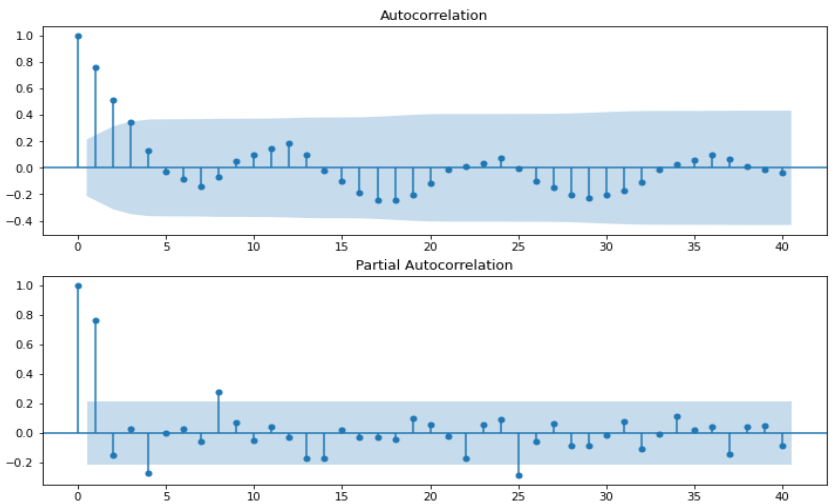

Fig. 7. ACF and PACF for education in urban. 

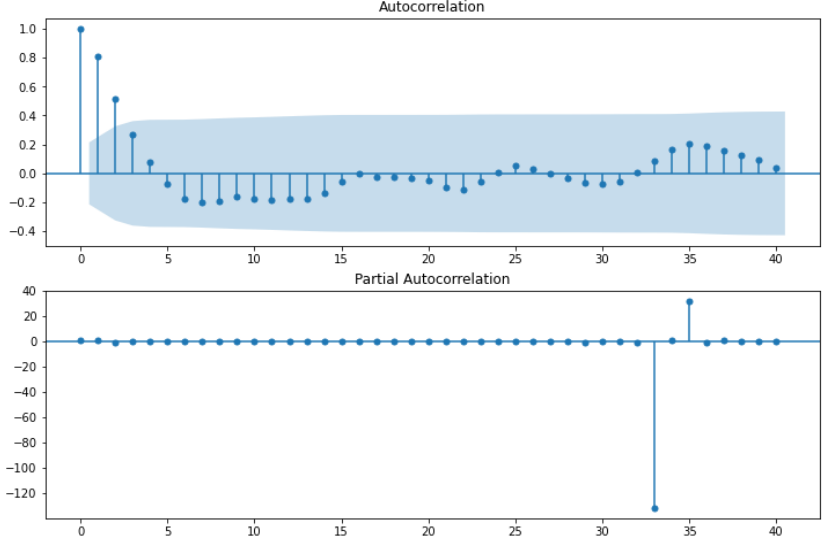

Fig. 8. ACF and PACF for fuel and light in urban.

In the Fig. 1 and 2, the ACF decays exponentially and the PACF shows a clear spike at lag $0 \& 1$. Then, PACF is cut after lag 1. Therefore, A non-seasonal AR(1) and seasonal $\mathrm{AR}(1)$ are may be a useful part for the model of food and beverages pan, tobacco and intoxicants in rural and MA operator of non-seasonal and seasonal has zero lag. In the Fig. 3 , the ACF curve has spike at lag 0 and the PACF shows a clear spike at lag 0. But, the PACF has spike lag 36s. Therefore, seasonal AR (1) and non-seasonal AR (0) are may be a useful part for the model of education in rural and MA operator of non-seasonal and seasonal has zero lag. In Fig. 4, the ACF shows a clear spike at lags $0,1 \& 2$ and the PACF has a no spike until lag 35. Then, the ACF is cut after lag 3. Therefore, A seasonal MA (0) and non-seasonal MA (2) may be a useful part for the model of fuel and light in rural and AR operator of non-seasonal and seasonal has zero lag.

In the Fig. 5, 6 and 7, the ACF decays exponentially and the PACF shows a clear spike at lag $0 \& 1$. Then, PACF is cut after lag 1. Therefore, A non-seasonal AR (1) and seasonal AR (1) may be a useful part for the model of food and beverages \& pan, tobacco, and intoxicants \& education in urban and MA operator of non-seasonal and seasonal has zero lag.

In the Fig. 8, the ACF shows a clear spike at lags $0,1 \& 2$ and the PACF has a no spike until lag 32. Then, the ACF is cut after lag 2. Therefore, A seasonal MA (0) and nonseasonal MA (2) may be a useful part of the model for fuel and light in urban and AR operator of non-seasonal and seasonal has zero lag.

\section{SARIMA MODEL}

The forecast equation of SARIMA $(1,1,0) *(1,1,0,12)$ for food and beverages in rural (FBR) of India is defined below, (Appendix -Table II).

$$
\begin{gathered}
F B R_{t}=F B R_{t-1}+F B R_{t-12}-F B R_{t-13}+ \\
0.5911\left[F B R_{t-13}-F B R_{t-12}-F B R_{t-25}+F B R_{t-24}\right]- \\
0.1984\left[F B R_{t-2}-F B R_{t-1}-F B R_{14}+F B R_{t-13}\right]+ \\
0.1173\left[F B R_{t-13}-F B R_{t-14}-F B R_{t-25}+F B R_{t-26}\right]
\end{gathered}
$$

The forecast equation of SARIMA $(1,0,0) *(1,0,0,12)$ for pan, tobacco and intoxicants in rural (PTIR) of India is defined below:

$$
\begin{aligned}
& \text { PTIR }_{t}=0.9998 \text { PTIR }_{t-1}+0.6080 \text { PTIR }_{t-12}- \\
& 0.6079 \text { PTI }_{t-13}
\end{aligned}
$$

The forecast equation of SARIMA $(0,1,0) *(1,1,0,12)$ for education in rural (EDR) of India is defined below:

$$
\begin{gathered}
E D R_{t}=E D R_{t-1}+E D R_{t-12}-E D R_{t-13}- \\
0.4891\left[E D R_{t-12}-E D R_{t-13}-E D R_{t-24}+E D R_{t-25}\right]
\end{gathered}
$$

The forecast equation of SARIMA $(0,1,2) *(0,1,0,12)$ for fuel and light in rural (FLR) of India is defined below:

$$
\begin{aligned}
& F L R_{t}=F L R_{t-1}+F L R_{t-12}-F L R_{t-13}+a_{t}- \\
& 0.5016 a_{t-1}-0.1957 a_{t-2}
\end{aligned}
$$

The forecast equation of SARIMA $(1,0,0) *(1,0,0,12)$ for food and beverages in urban (FBU) of India is defined below:

$$
\begin{aligned}
& F B U_{t}=0.9996 F B U_{t-1}+0.5147 F B U_{t-12}- \\
& 0.5145 F B U_{t-13}
\end{aligned}
$$

The forecast equation of SARIMA $(1,1,0) *(1,1,0,12)$ for pan, tobacco and intoxicants in urban (PTIU) of India is defined below:

$$
\begin{gathered}
\text { PTIU }_{t}=\text { PTIU }_{t-1}+P T I U_{t-12}-P T I U_{t-13}+ \\
0.3371\left[\text { PTIU }_{t-13}-\text { PTIU }_{t-12}-P T I U_{t-25}+P T I U_{t-24}\right]- \\
0.5130\left[\text { PTIU }_{t-2}-\text { PTIU }_{t-1}-P T I U_{14}+P T I U_{t-13}\right]- \\
0.1729\left[\text { PTIU }_{t-13}-\text { PTIU }_{t-14}-\text { PTIU }_{t-25}+\text { PTIU }_{t-26}\right]
\end{gathered}
$$

The forecast equation of SARIMA $(1,1,0) *(1,1,0,12)$ for education (EDU) in urban of India is defined below:

$$
\begin{gathered}
E D U_{t}=E D U_{t-1}+E D U_{t-12}-E D U_{t-13}+ \\
0.4608\left[E D U_{t-13}-E D U_{t-12}-E D U_{t-25}+E D U_{t-24}\right]+ \\
0.0512\left[E D U_{t-2}-E D U_{t-1}-E D U_{14}+E D U_{t-13}\right]- \\
0.0236\left[E D U_{t-13}-E D U_{t-14}-E D U_{t-25}+E D U_{t-26}\right]
\end{gathered}
$$

The forecast equation of SARIMA $(0,1,2) *(0,1,0,12)$ for fuel and light in urban (FLU) of India is defined below:

$$
\begin{aligned}
& F L U_{t}=F L U_{t-1}+F L U_{t-12}-F L U_{t-13}+a_{t}- \\
& 0.6006 a_{t-1}-0.3116 a_{t-2}
\end{aligned}
$$

\section{Model validation}

The data in Table III support the conclusion that the pvalues of all major variables are higher than level of significance (i.e., alpha $=0.05$ ) for all of the main variables. The predicted residuals did not offer adequate evidence to reject the null hypothesis $(\mathrm{H} 0)$ at the $5 \%$ level of significance, as a result of which the hypothesis was not rejected. As a result, the forecast residuals of the eight major variables are dispersed in an independent manner. 
TABLE III: RESULT OF LJUNG BOX METHOD

\begin{tabular}{ccccccccc}
\hline \hline & \multicolumn{4}{c}{ Rural } & \multicolumn{5}{c}{ Urban } \\
\cline { 2 - 9 } & FB & PTI & ED & FL & FB & PTI & ED & FL \\
\hline \hline 1_b statistic & 0.0885 & 0.0002 & 0.0009 & 0.0078 & 0.0230 & 0.0039 & 0.0017 & 0.0015 \\
p_value & 0.7660 & 0.9883 & 0.9767 & 0.9298 & 0.8794 & 0.9504 & 0.9670 & 0.9696 \\
\hline \hline
\end{tabular}

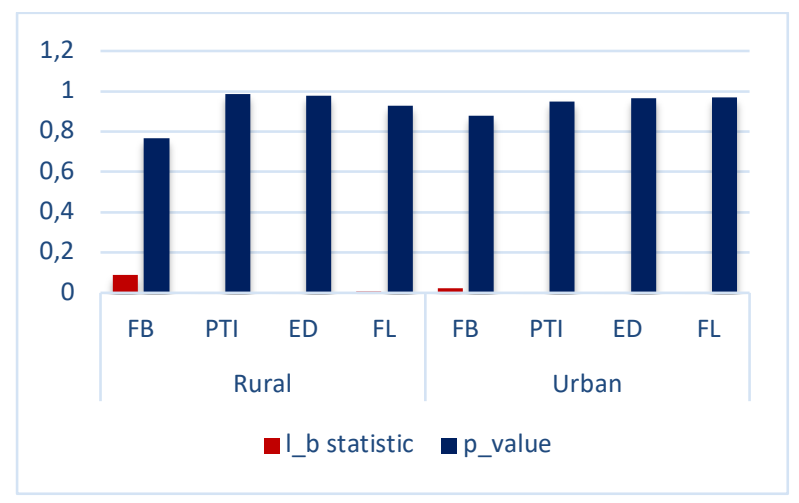

Fig. 9. Validation results.

The forecasted and inflation rate for CPI of all target variables. The forecast values with inflation rate for all target variables of this study for the period of January- 2022 to December - 2022 (Appendix -Table IV).

In the year 2021, as compare first month and last month of CPI rate for PTIR and PTIU has increased at the rate of 9.5 and 16.5, respectively. And the inflation rate of PTIR and PTIU in December 2021 has a lesser value as compared to January 2021 and December 2020. Therefore, those prices rise at moderately and this inflation known as walking and trotting inflation at economically.

In the year 2021, as compare first month and last month of CPI rate for EDR and EDU has increased at the rate of 3.8 and 4.6, respectively. And the inflation rate of EDR and EDU in December 2021 has a greater value as compared to January 2021 and December 2020. Therefore, those prices rise at moderately and this inflation known as walking and trotting inflation at economically.

In the year 2021, as compare first month and last month of CPI rate for FLR and FLU has increased at the rate of 0.6 and 9.3, respectively. And the inflation rate of FLR and FLU on December 2021 has a greater value as compared to January 2021 and December 2020.But, the price of FLU rise at moderately and this inflation known as walking and trotting inflation \& the price of FLR rise at very slowly and this inflation known as creeping inflation at economically.

In the year 2022, as compare first month and last month of CPI rate for FBR and FBU has increased at the rate of 9 and 1.9 , respectively. And the inflation rate of FBR and FBU on December 2022 has a less value as compared to January 2022 and December 2021.But, the price of FBR rise at moderately and this inflation known as walking and trotting inflation and the price of FBU rise at very slowly and this inflation known as creeping inflation at economically.

In the year 2022, as compare first month and last month of CPI rate for PTIR and PTIU has increased at the rate of 5.6 and 18.1, respectively. And the inflation rate of PTIR and PTIU in December 2022 has a lesser value as compared to January 2022and December 2021. Therefore, those prices rise at moderately and this inflation known as walking and trotting inflation at economically.
In the year 2022, as compare first month and last month of CPI rate for EDR and EDU has increased at the rate of 2.9 and 4.3, respectively. And the inflation rate of EDR and EDU in December 2022 has a lesser value as compared to January 2022and December 2021. Therefore, those price rise at very slowly and this inflation known as creeping inflation at economically.

In the year 2022, as compare first month and last month of CPI rate for FLR and FLU has increased at the rate of 0.6 and 9.4, respectively. And the inflation rate of FLR on December 2021 has a greater value as compared to January 2022 and the inflation rate of FLU on December 2021 has a lesser value as compared to January 2022 Therefore, the price of FLU rise at moderately and this inflation known as walking and trotting inflation and the price of FLR rise at very slowly and this inflation known as creeping inflation at economically.

\section{CONCLUSION}

The CPI in urban and rural regions of India, including food and beverages, pan, tobacco \& intoxicants, fuel \& light, and education, as well as the rate of inflation are predicted. In order to predict CPI and, therefore, inflation, it was determined that the Seasonal ARIMA model would be the most suitable model. We suggest that the Reserve Bank of India adopt this model and distribute it to its customers, since predictions are helpful for improved resource allocation and decision making.

\section{REFERENCES}

[1] S. O. Adams, A. Awujola and A. I. Alumgudu, "Modeling Nigeria's Consumer Price index using ARIMA model," International Journal of Development and Economic Sustainability 2(2): 37-47, 2014.

[2] X. Chen, X. Cai, J. Liang and Q. Liu, "Ensemble learning multiple LSSVR with improved harmony search algorithm for short-term traffic flow forecasting," IEEE Access 12(6): 9347-57, 2018.

[3] V. Deneshkumar, K. Senthamarai Kannan and M. Manikandan, "Designing of neural network models for agricultural forecasting," Journal of Statistics and Management Systems. 18(6): 547-59, 2015.

[4] D. Venugopal, S. K. Kaliyaperumal and S. M. Niraikulathan, "Stock Market Trend Prediction Using Hidden Markov Model," Forecasting in Mathematics 12:87, 2020.

[5] T. Dimri, S. Ahmad and M. Sharif, "Time series analysis of climate variables using seasonal ARIMA approach," Journal of Earth System Science 129(1):1-6, 2020.

[6] W. Dongdong, "The consumer price index forecast based on ARIMA model," WASE International Conference on Information Engineering 1, 307-310, IEEE, 2010.

[7] M. Iqbal and A. Naveed, "Forecasting inflation: Autoregressive integrated moving average model," European Scientific Journal 12(1):83-92, 2016.

[8] S. V. Kumar and L. Vanajakshi, "Short-term traffic flow prediction using seasonal ARIMA model with limited input data," European Transport Research Review 7(3):1-9, 2015.

[9] J. Mohamed, "Time Series Modeling and Forecasting of Somaliland Consumer Price Index: A Comparison of ARIMA and Regression with ARIMA Errors," American Journal of Theoretical and Applied Statistics 9(4):143-53, 2020.

[10] Y. Mwanga, "Arima Forecasting Model for Uganda's Consumer Price Index," American Journal of Theoretical and Applied Statistics 9(5):238, 2020. 
[11] H. Norbert, A. Wanjoya and A. Waititu, "Modeling and forecasting consumer price index (Case of Rwanda)," American Journal of Theoretical and Applied Statistics 5, 101-7, 2016.

[12] M. Salzano and D. Colander, Complexity Insights for Economic Policy, Milan: Springer-Verlag. 10, 2007.
[13] C. Singla, P. K. Sarangi, S. Singh and A. K. Sahoo, "Modeling Consumer Price Index: An Empirical Analysis Using Expert Modeler,' Journal of Technology Management for Growing Economies 10(1):43$50,2019$.

APPENDIX

TABLE I: SARIMA MODEL FOR TARGET VARIABLES

\begin{tabular}{|c|c|c|c|c|c|c|c|c|c|}
\hline SARIMA Model & AIC & $\mathrm{BIC}$ & Factors & Co- ef & SE & $\mathrm{Z}$ & $\mathrm{p}>|\mathrm{z}|$ & {$[0.025$} & $0.975]$ \\
\hline SARIMA $(1,1,0)^{*}$ & & & ar.L1 & 0.1984 & 0.100 & 1.990 & 0.047 & 0.003 & 0.394 \\
\hline$(1,1,0,12)$ for $F B R$ & 315.085 & 322.342 & ar.S.L12 & -0.5911 & 0.081 & -7.280 & 0.000 & -0.750 & -0.432 \\
\hline SARIMA $(1,0,0)^{*}$ & 341800 & 340507 & ar.L1 & 0.9998 & 0.001 & 1315.592 & 0.000 & 0.998 & 1.001 \\
\hline$(1,0,0,12)$ for PTIR & 341.899 & 349.592 & ar.S.L12 & 0.6080 & 0.229 & 2.651 & 0.008 & 0.158 & 1.058 \\
\hline $\begin{array}{l}\text { SARIMA }(0,1,0)^{*} \\
(1,1,0,12) \text { for EDR }\end{array}$ & 216.014 & 220.852 & ar.S.L12 & -0.4891 & 0.050 & -9.718 & 0.000 & -0.588 & -0.390 \\
\hline SARIMA $(0,1,2)^{*}$ & 258520 & 265786 & ma.L1 & 0.5016 & 0.117 & 4.284 & 0.000 & 0.272 & 0.731 \\
\hline$(0,1,0,12)$ for FLR & 258.529 & 265.786 & ma.L2 & 0.1957 & 0.104 & 1.881 & 0.060 & -0.008 & 0.400 \\
\hline SARIMA $(1,0,0)^{*}$ & & & ar.L1 & 0.9996 & 0.001 & 670.624 & 0.000 & 0.997 & 1.003 \\
\hline$(1,0,0,12)$ for $\mathrm{FBU}$ & 401.469 & 409.163 & ar.S.L12 & 0.5147 & 0.104 & 4.939 & 0.000 & 0.310 & 0.719 \\
\hline SARIMA $(1,1,0)^{*}$ & 22148 & 714 & ar.L1 & 0.5130 & 0.101 & 5.083 & 0.000 & 0.315 & 0.711 \\
\hline$(1,1,0,12)$ for PTIU & 221.458 & 28.714 & ar.S.L12 & -0.3371 & 0.171 & -1.974 & 0.048 & -0.672 & -0.002 \\
\hline SARIMA $(1,1,0)^{*}$ & 00 & 2 & ar.L1 & -0.0512 & 0.188 & -0.273 & 0.785 & -0.419 & 0.317 \\
\hline$(1,1,0,12)$ forEDU & 32.00 & .2 & ar.S.L12 & -0.4608 & 0.217 & -2.121 & 0.034 & -0.886 & -0.035 \\
\hline SARIMA $(0,1,2)^{*}$ & & & ma.L1 & 0.6006 & 0.121 & 4.961 & 0.000 & 0.363 & 0.838 \\
\hline$(0,1,0,12)$ for FLU & 33 & 8.368 & ma.L2 & 0.3116 & 0.098 & 3.185 & 0.001 & 0.120 & 0.503 \\
\hline
\end{tabular}

TABLE IV: CPI FOR FOUR MAIN VARIABLES OF URBAN AND RURAL ON 2022

\begin{tabular}{|c|c|c|c|c|c|}
\hline \multirow[b]{2}{*}{ Months } & \multirow[b]{2}{*}{ Commodity Description } & \multicolumn{2}{|c|}{ Rural } & \multicolumn{2}{|l|}{ Urban } \\
\hline & & $\begin{array}{l}\text { Current } \\
\text { Month } \\
\end{array}$ & $\begin{array}{l}\text { Inflation } \\
(\mathrm{Y}-\mathrm{O}-\mathrm{Y}) \\
\end{array}$ & Current Month & $\begin{array}{l}\text { Inflation } \\
(\mathrm{Y}-\mathrm{O}-\mathrm{Y})\end{array}$ \\
\hline Jan -2022 & Food and Beverages & 168.1 & 6.87 & 166.2 & 2.34 \\
\hline Jan -2022 & Pan, Tobacco and Intoxicants & 194.9 & 5.29 & 209.9 & 8.93 \\
\hline Jan - 2022 & Education & 168.1 & 2.56 & 161.1 & 3.07 \\
\hline Jan -2022 & Fuel and Light & 153.1 & 0.92 & 160 & 8.99 \\
\hline Feb -2022 & Food and Beverages & 165.5 & 6.29 & 165.4 & 2.73 \\
\hline Feb -2022 & Pan, Tobacco and Intoxicants & 195.1 & 5.18 & 211.1 & 8.87 \\
\hline Feb - 2022 & Education & 168.4 & 2.62 & 161.2 & 3.07 \\
\hline Feb -2022 & Fuel and Light & 155.1 & 0.91 & 165.4 & 8.74 \\
\hline Mar - 2022 & Food and Beverages & 164.3 & 5.93 & 164.9 & 3 \\
\hline Mar - 2022 & Pan, Tobacco and Intoxicants & 195.5 & 5.99 & 212.3 & 8.82 \\
\hline Mar - 2022 & Education & 167.8 & 2.5 & 161.4 & 3.07 \\
\hline Mar - 2022 & Fuel and Light & 156.2 & 0.9 & 167.9 & 8.6 \\
\hline Apr -2022 & Food and Beverages & 168 & 6.73 & 166.5 & 2.02 \\
\hline Apr -2022 & Pan, Tobacco and Intoxicants & 195.7 & 4.93 & 217 & 8.99 \\
\hline Apr -2022 & Education & 168.4 & 2.43 & 165.5 & 3.57 \\
\hline Apr -2022 & Fuel and Light & 151.2 & 0.93 & 163.6 & 8.85 \\
\hline May - 2022 & Food and Beverages & 167.2 & 6.16 & 166.2 & 2.21 \\
\hline May - 2022 & Pan, Tobacco and Intoxicants & 195.7 & 4.88 & 220.5 & 9.05 \\
\hline May -2022 & Education & 168.6 & 2.43 & 165.9 & 3.62 \\
\hline May - 2022 & Fuel and Light & 149.2 & 0.95 & 162.7 & 8.9 \\
\hline Jun - 2022 & Food and Beverages & 168.3 & 5.85 & 166.6 & 1.83 \\
\hline Jun - 2022 & Pan, Tobacco and Intoxicants & 199.8 & 3.31 & 223.2 & 9.09 \\
\hline Jun - 2022 & Education & 168.8 & 2.24 & 162 & 2.79 \\
\hline Jun - 2022 & Fuel and Light & 147.7 & 0.96 & 163.6 & 8.85 \\
\hline Jul - 2022 & Food and Beverages & 171.1 & 6.08 & 167.4 & 1.45 \\
\hline Jul -2022 & Pan, Tobacco and Intoxicants & 199.3 & 3.59 & 223.7 & 9.07 \\
\hline Jul - 2022 & Education & 169.9 & 2.16 & 164.6 & 2.94 \\
\hline Jul - 2022 & Fuel and Light & 148.6 & 0.95 & 164.8 & 8.78 \\
\hline Aug - 2022 & Food and Beverages & 171.9 & 5.91 & 167.7 & 1.21 \\
\hline Aug - 2022 & Pan, Tobacco and Intoxicants & 200 & 3.31 & 225 & 9.06 \\
\hline Aug - 2022 & Education & 168.8 & 1.87 & 164.4 & 2.69 \\
\hline Aug - 2022 & Fuel and Light & 149.2 & 0.95 & 163.7 & 8.84 \\
\hline Sep -2022 & Food and Beverages & 174.9 & 6.26 & 168.5 & 0.72 \\
\hline Sep -2022 & Pan, Tobacco and Intoxicants & 199.9 & 3.31 & 225.1 & 9.01 \\
\hline Sep -2022 & Education & 170 & 1.98 & 165.1 & 2.87 \\
\hline Sep -2022 & Fuel and Light & 149.6 & 0.94 & 163.6 & 8.85 \\
\hline Oct -2022 & Food and Beverages & 178.5 & 6.38 & 169.1 & 0.3 \\
\hline Oct -2022 & Pan, Tobacco and Intoxicants & 200.1 & 3.2 & 225.4 & 8.99 \\
\hline Oct -2022 & Education & 169.4 & 1.74 & 165.6 & 2.86 \\
\hline Oct -2022 & Fuel and Light & 150.3 & 0.94 & 163.8 & 8.84 \\
\hline Nov -2022 & Food and Beverages & 180 & 6.01 & 169.1 & 0.3 \\
\hline Nov -2022 & Pan, Tobacco and Intoxicants & 200.2 & 3.2 & 226.6 & 8.94 \\
\hline Nov -2022 & Education & 170.4 & 1.91 & 166 & 2.91 \\
\hline Nov -2022 & Fuel and Light & 151.5 & 0.93 & 164.4 & 8.8 \\
\hline Dec -2022 & Food and Beverages & 177.1 & 4.3 & 168.1 & 0.84 \\
\hline Dec -2022 & Pan, Tobacco and Intoxicants & 200.5 & 3.03 & 228 & 8.99 \\
\hline Dec -2022 & Education & 171 & 1.97 & 165.4 & 2.8 \\
\hline Dec - 2022 & Fuel and Light & 153.7 & 0.92 & 169.4 & 8.52 \\
\hline
\end{tabular}

